\title{
Marketed as Authorized Generic under New Drug Application
}

National Cancer Institute

\section{Source}

National Cancer Institute. Marketed as Authorized Generic under New Drug Application. NCl Thesaurus. Code C73605.

A category specifying that a drug is marketed as the brand-generic version of the product by the holder of an approved New Drug Application. 